\title{
A aprendizagem significativa no ensino de engenharia de controle e automação
}

\author{
Adelson Siqueira Carvalho, UFRGS, adelsonsc@yahoo.com.br \\ Dante Augusto Couto Barone, UFRGS, barone@inf.ufrgs.br \\ Milton Antônio Zaro, UFRGS, zaro@ufrgs.br
}

\begin{abstract}
Resumo: Este trabalho apresenta uma proposta para prática docente dentro da disciplina de controle avançado em um curso de engenharia de controle e automação. A fundamentação teórica da proposta é a teoria da aprendizagem significativa de David Ausubel associada aos mapas conceituais de Joseph Novak. Para nortear o projeto do experimento didático pedagógico e a metodologia da prática docente proposta é utilizada a teoria da avaliação mediadora da Jussara Hoffmann. Instrumentos para coleta de dados são propostos para suportar as teorias utilizadas na concepção do experimento. Os resultados da aplicação do experimento didático pedagógico concebido são apresentados na forma de mapas conceituais dos alunos, não de maneira estática, mas sim dinâmica, evidenciando a evolução na rede de conceitos do aluno. A análise dos mapas é feita sob a luz da teoria da aprendizagem significativa. As considerações acerca deste novo método são apresentadas ao final do trabalho.
\end{abstract}

Palavras chave: aprendizagem significativa, mapas conceituais, experimento didáticopedagógico.

\section{Meaningful learning in the teaching of control engineering and automation}

Abstract: This paper presents a proposal for teaching practice within the discipline of a course in advanced control engineering and automation control. The theoretical basis of the proposal is a significant learning theory of David Ausubel associated with concept mapping Joseph Novak. To guide the design of the teaching experiment methodology of teaching and teaching practice is proposed to the theory of assessment of mediating Jussara Hoffmann. Instruments for data collection are proposed to support the theories used in designing the experiment. The results of the implementation of the teaching experiment designed teaching are presented in the form of concept maps of students, not a static but dynamic, showing developments in the network of concepts the student. The analysis of maps is done under the theory of meaningful learning. The considerations about this new method is presented to the end of the work.

Keywords: meaningful learning, concept maps, didactic-pedagogic experiment.

\section{Introdução}

A ênfase no ensino de técnicas no lugar de conceitos resulta em um rápido esquecimento por parte dos alunos. O ensino da teoria desvinculado dos aspectos práticos não prepara adequadamente o aluno para o exercício da profissão. (VALLIM et al., 2000).

Atualmente, iniciativas tem surgido com o intuito de alterar a realidade apresentada por Vallim et al. (2000), um dos caminhos que surge como possível solução para este problema é a teoria da aprendizagem significativa de Ausubel e sua utilização na prática docente. Diversos trabalhos tem utilizado tal teoria para melhoria do processo de ensino-aprendizagem tais como Moreira e Dionisio (1975) e Silveira (2008).

Segundo Schinaid et al. (2003) as recomendações da Accreditation Board for Engineering and Technology (ABET), instituição norte-americana que procura estabelecer critérios de qualidade específicos para cada habilitação, os cursos de 
graduação devem estimular a capacidade para aplicar conhecimento de matemática, ciências e engenharia; projetar e conduzir experimentos; analisar e interpretar resultados; projetar um sistema, componente ou processo para atender a determinados requisitos; atuar em equipes multidisciplinares; identificar, formular e resolver problemas de engenharia; poder compreender a natureza da ética e da responsabilidade profissional; comunicar-se efetivamente (por escrito e oralmente); entender o impacto das soluções da engenharia no contexto social e ambiental; buscar a aprendizagem permanente; e ainda usar técnicas e ferramentas modernas para o exercício da prática da engenharia.

Tendo em vista este contexto o presente trabalho apresenta uma proposta de ensino baseada na aprendizagem significativa complementada com a avaliação mediadora para o ensino de engenharia de controle e automação, especificamente a disciplina de controle avançado de processos. Um experimento didático-pedagógico é concebido e caracterizado a partir de um plano de aula modificado que favoreça a autonomia do aprendiz em formação e, ao mesmo tempo, proporcione a utilização de instrumentos para a coleta de dados para posterior análise sob a luz das teorias envolvidas.

As teorias selecionadas para a concepção didático-pedagógica desta proposta tem, como principal argumento, a tentativa de aproximação do ensino de engenharia de controle e automação, tipicamente comportamentalista, ao paradigma mais adequado para a construção do saber, aprendizagem de conceitos e das competências inerentes a este profissional. Estes pressupostos teóricos estão galgados na teoria da aprendizagem significativa de David Ausubel (AUSUBEL et al., 1978), os mapas conceituais de Joseph Novak (NOVAK e CAÑAS, 2006) e a avaliação mediadora de Jussara Hoffman (HOFFMANN, 1996).

A aprendizagem significativa é utilizada como teoria da aprendizagem central neste trabalho devido a sua aderência ao ensino de engenharia. Tipicamente as aulas em um curso de engenharia possuem um público-alvo que já passou pelos estágios do desenvolvimento cognitivo, definidos por Piaget (PIAGET, 2007), ou seja, os alunos já possuem as estruturas cognitivas necessárias para realizar operações sobre conceitos abstratos, enquadrando-se, portanto na categoria de operatório formal. Os alunos são expostos tipicamente à aulas expositivas e também aulas de descoberta, em ambos os casos, os alunos possuem algum esquema de significação que favorecem a aprendizagem. Ausubel considera que este esquema de significação na verdade são os subsunçores necessários para o surgimento da aprendizagem significativa.

Os mapas conceituais serão utilizados neste trabalho como formas de representação do conhecimento do indivíduo, por meio destes, será possível verificar a evolução da rede de ligações conceituais presentes em suas estruturas cognitivas.

Um ambiente que proporcione estas experiências associado à uma prática docente e plano de aula adequado ao modelo mais participativo de ensinoaprendizagem, é de potencial relevância para o desenvolvimento da chamada aprendizagem significativa. Para tanto certos aspectos não podem deixar de ser destacados, por exemplo, o processo avaliativo.

É comum em cursos de engenharia que os professores, exímios transmissores de conhecimento - como se o conhecimento pudesse ser transmitido e não construído entendem como avaliação um processo de confronto entre as respostas do professor e as respostas do aluno, buscando uma medida de aproximação entre as duas para gerar uma provável nota ou conceito que representa todo o aprendizado do indivíduo ao longo de meses de aula. 
Segundo Hoffmann (1994):

Acompanhamento do processo de construção de conhecimento implica favorecer o desenvolvimento do aluno, orientá-lo nas tarefas, oferecer-lhe novas leituras ou explicações, sugerir-lhe investigações, proporcionar-lhe vivências enriquecedoras e favorecedoras à sua ampliação do saber.

No contexto da formação fundado em paradigmas que se constituem a partir do construtivismo, das pedagogias críticodialógicas e sócio-interacionistas, a avaliação educacional não é algo que está dissociada do grande conjunto processual que configura a educação formal escolar e universitária. Ela é intrínseca à prática educativa, ao ensino e à aprendizagem (AHLERT, 2002).

Entendendo que o processo de avaliação da aprendizagem deve ser contínuo e presente ao longo de todo o período de ensino-aprendizagem, uma avaliação estanque como uma prova para verificação do êxito ao solucionar um problema pontual, não será capaz de representar todo o conhecimento construído nas estruturas cognitivas do aluno. Logo este trabalho surge como uma proposta para atender estes aspectos dentro de um curso de engenharia de controle e automação.

Tendo em vista este contexto faz-se necessário explicitar o quão relevante, bem como situar o leitor no que tange esta proposta, para tanto, na próxima seção deste capítulo apresentar-se-á uma breve explanação sobre engenharia de controle e automação. A seguir são apresentadas as teorias da aprendizagem que compõem o referencial teórico para a formulação de um novo modelo pedagógico para a prática docente em engenharia de controle e automação. A caracterização do modelo proposto também é apresentada seguida dos resultados e considerações finais do estudo.

\section{Engenharia de controle e controle avançado}

O curso superior de engenharia em controle e automação, não é tão antigo quanto os cursos de engenharia elétrica, mecânica e civil, mas também padece dos mesmos problemas quanto ao modelo pedagógico vigente e à prática docente. Existe nele também a predominância do modelo instrucional comportamentalista baseado em aulas expositivas, exercícios descontextualizados e memorização de técnicas em lugar de construção de conceitos e sistemas de conceitos, solução de problemas e situações de construção do conhecimento a partir da interação e da manipulação do objeto de estudo.

Dentro do currículo tradicional de um engenheiro de controle e automação, as disciplinas do ciclo básico são tipicamente as disciplinas do ciclo básico de qualquer outro curso de engenharia: cálculo, álgebra, física, estatística, introdução à engenharia, dentre outras. No ciclo profissionalizante ou intermediário, há uma predominância das disciplinas de fundamentação eletro-eletrônica, assim como mecânica geral, termodinâmica, fenômenos de transporte, etc. A diferenciação do engenheiro de controle e automação com relação os demais engenheiros fica a cargo do núcleo específico, com disciplinas tecnológicas: controladores lógicos programáveis, sistemas de supervisão, equipamentos e processos industriais, instrumentação industrial, redes industriais, etc. Além das disciplinas do núcleo específico que cuidam da engenharia de controle propriamente dita: fundamentos matemáticos para controle, controle clássico, controle moderno, controle digital, controle avançado, laboratório de controle, etc.

A disciplina de controle avançado tem a função de apresentar ao aluno conteúdos não contemplados pelas outras disciplinas, como o controle baseado em Inteligência Artificial (I.A.), controle robusto, controle ótimo, controle preditivo, etc. Neste escopo, surge uma certa liberdade em termos de conteúdo contemplado que muda de instituição para instituição de ensino, sobretudo pela formação acadêmica de cada profissional responsável pela disciplina. 
Considerando o universo ou campo empírico escolhido para a realização dos experimentos deste trabalho, a disciplina de controle avançado tem seu conteúdo composto basicamente de duas unidades ou partes, a primeira parte referente à identificação de sistemas, ou obtenção de modelos dos sistemas reais a partir de dados coletados do processo, utilizando para isso RNA's (Redes Neurais artificiais), na segunda parte é apresentado o controle fuzzy de processos industriais. Este conteúdo é assim organizado com o intuito de apresentar ao aluno métodos não convencionais de modelagem de sistemas e controle de processos, basicamente por meio da inteligência artificial.

Nas próximas seções é apresentada a fundamentação teórica acerca da aprendizagem significativa e dos mapas conceituais.

\section{A aprendizagem significativa}

A teoria da aprendizagem significativa foi criada por Ausubel sendo, posteriormente, propagada e investigada em diversas áreas do conhecimento por pesquisadores como Novak (1977), Moreira (2006) entre outros.

Ausubel propõe que, para que a aprendizagem tenha realmente efeito modificador nas estruturas cognitivas do indivíduo, é necessário que ela seja significativa. Ao lançar mão desta premissa, Ausubel sugere a necessidade de que se defina a aprendizagem significativa e seu oposto, a aprendizagem não significativa.

Segundo Ausubel et al. (1978):

É importante reconhecer que a aprendizagem significativa (independente do tipo) não quer dizer que a nova informação forma, simplesmente, uma espécie de ligação com elementos preexistentes na estrutura cognitiva. Ao contrário, somente na aprendizagem mecânica é que uma simples ligação, arbitrária e não substantiva, ocorre com a estrutura significativa preexistente. $\mathrm{Na}$ aprendizagem significativa, o processo de aquisição de informações resulta em mudança, tanto da nova informação adquirida como no aspecto especificamente relevante da estrutura cognitiva ao qual essa se relaciona.

Ausubel destaca ainda que, a aprendizagem para ser significativa necessita de alguns pontos em particular: que o aluno esteja motivado, interessado em aprender o conteúdo apresentado; que o material seja potencialmente significativo e que o aluno possua os subsunçores necessários para aprender o conteúdo.

Subsunçor é um conceito cunhado por Ausubel para representar o conhecimento prévio que o aluno possui sobre um dado conteúdo e que está presente em suas estruturas cognitivas. De acordo com a teoria da aprendizagem significativa se os subsunçores necessários à aprendizagem de um novo conteúdo estiverem presentes nas estruturas cognitivas do indivíduo, a conexão entre este subsunçor e o novo conteúdo assimilado pelo aluno poderá ocorrer de forma bastante "forte", ou seja, a conexão entre estes elementos não será apenas uma ligação "fraca" oriunda tipicamente da memorização e da aprendizagem mecânica.

Apesar de parecer completamente ineficiente em termos de aprendizagem, a aprendizagem mecânica possui um papel importante dentro da teoria da aprendizagem significativa, que é de construir subsunçores quando estes não existem.

Dentre as funções que antecedem a aprendizagem significativa existem: a aprendizagem representacional, aprendizagem de conceitos e aprendizagem proposicional.

Aprendizagem representacional trata-se apenas da atribuição de significado a símbolos. A aprendizagem de conceitos é aquela que utiliza os atributos em comum para categorizar ou classificar os objetos. A aprendizagem proposicional é aquela que transcende a representacional no sentido de que ultrapassa a simples soma de 
significados, e alcança o entendimento da proposição que é formada pelos conceitos e significados que a compõe.

Mesmo fazendo a diferenciação entre estes três tipos de aprendizagem ainda assim não é possível diferenciar uma aprendizagem significativa de uma aprendizagem não significativa. Isto se deve ao fato de que, os aprendizes conseguem memorizar símbolos, conceitos, proposições e até mesmo solução de problemas.

Para superar este inconveniente de simulação da aprendizagem significativa por parte dos aprendizes podem-se utilizar alguns artifícios como: formular de maneira diferente da apresentada durante a exposição os questionamentos dos principais conceitos envolvidos. De forma análoga, a utilização de problemas não apresentados durante a etapa de exposição devem ser utilizados para verificação da capacidade do aprendiz em solucionar problemas fazendo uso da generalização e extensão do que foi aprendido, este é um dos indícios da verdadeira aprendizagem significativa.

Para que se entenda razoavelmente como ocorre o processo de assimilação durante a aprendizagem significativa pode-se recorrer ao esquema apresentado por Moreira (2006):

Passa pela idéia de que uma nova informação que possui potencial de significado é apresentada e logo relacionada a um dado subsunçor já existente na estrutura cognitiva, o que ocorre é o produto desta interação que dá origem a um novo complemento de informação modificada e estrutura cognitiva modificada. Ou seja, tanto a informação nova muda quanto o subsunçor muda passando a ser mais abrangente e mais forte podendo ser utilizado para um conjunto maior de novas informações.

Isto pode ser resumido e expresso pela seguinte equação:

$\mathrm{O}$ conceito a $\rightarrow$ a' sempre que em contato com o seu correspondente subsunçor A, que também se torna A', $\log$ a . A $\rightarrow$ a'. A'.

Ausubel ao conceber a aprendizagem significativa destacou o que ocorre após o processo de assimilação, trata-se da assimilação obliteradora, tanto subsunçor quanto o conceito se modificam durante a assimilação e tornam-se uma só coisa, fazendo com que o aprendiz perca a capacidade de diferenciar o particular.

Pensando em termos de avaliação de aprendizagem, isso determina a necessidade de formular os questionamentos tomando como base os conceitos mais gerais para que se verifique a relação destes com os casos particulares e não somente a verificação dos conceitos mais específicos, pois estes ao passar pelo processo de assimilação e assimilação obliteradora deformam o que foi exposto. Desta forma, testes de verificação que confrontam a resposta do aluno e comparam com a resposta do professor são desaconselhados, pois apenas buscam testar a capacidade de memorização do aprendiz nos conceitos particulares e não o entendimento dos conceitos mais gerais que se formam em suas estruturas cognitivas.

\section{Mapas conceituais}

Os mapas conceituais são uma forma de representação do conhecimento criada por Joseph Novak, a partir da teoria da aprendizagem significativa de Ausubel, para representar graficamente o conhecimento presente nas estruturas cognitivas do indivíduo.

Novak desenvolveu esta ferramenta a partir de conceitos presentes na teoria da aprendizagem significativa de David Ausubel. A teoria sugere que o conhecimento se organiza nas estruturas cognitivas do indivíduo a partir de ligações entre conceitos, conceitos estes adquiridos durante a interação entre o indivíduo o objeto de estudo. Os conceitos ao se conectarem uns aos outros, se estruturam de forma hierárquica onde os conceitos mais gerais subordinam os mais específicos ou particulares. 
Um aspecto interessante sobre os mapas conceituais é suas possibilidades de utilização na prática docente. Segundo Moreira (1997) os mapas conceituais podem ser utilizados como:

$\checkmark$ Organizadores de conteúdo em cursos;

$\checkmark$ Estruturação de uma unidade de ensino para uma aula, mostrando relações entre os conceitos envolvidos;

$\checkmark$ Planejamento de currículo;

$\checkmark$ Instrumento de avaliação da aprendizagem.

Neste trabalho optou-se por utilizar os mapas conceituais de três dessas maneiras, estruturação de conteúdos, estruturação dos conceitos em uma aula expositiva e forma que é a mais importante: instrumento de avaliação da aprendizagem de forma dinâmica evolutiva e considerando a produção do aluno.

Atualmente a pesquisa sobre os mapas conceituais é desenvolvida em diversos pontos do mundo, mas seu criador, Joseph Novak, e colaboradores continuam desenvolvendo outros tipos de aplicações e melhorias dos mapas conceituais no IHMC (Institute for Human and Machine Cognition), sobre supervisão de Novak e colaboração de Alberto Cañas, criador do Cmap Tools, um software que auxilia na construção de mapas conceituais. O software em questão é utilizado neste trabalho para produzir os mapas conceituais apresentados.

Na Figura 1 é apresentado um mapa conceitual sobre as relações entre os principais conceitos da teoria da aprendizagem significativa. A aprendizagem significativa foi utilizada como teoria da aprendizagem que serviu como base para o desenvolvimento dos mapas conceituais e aqui são utilizados para explicá-la.

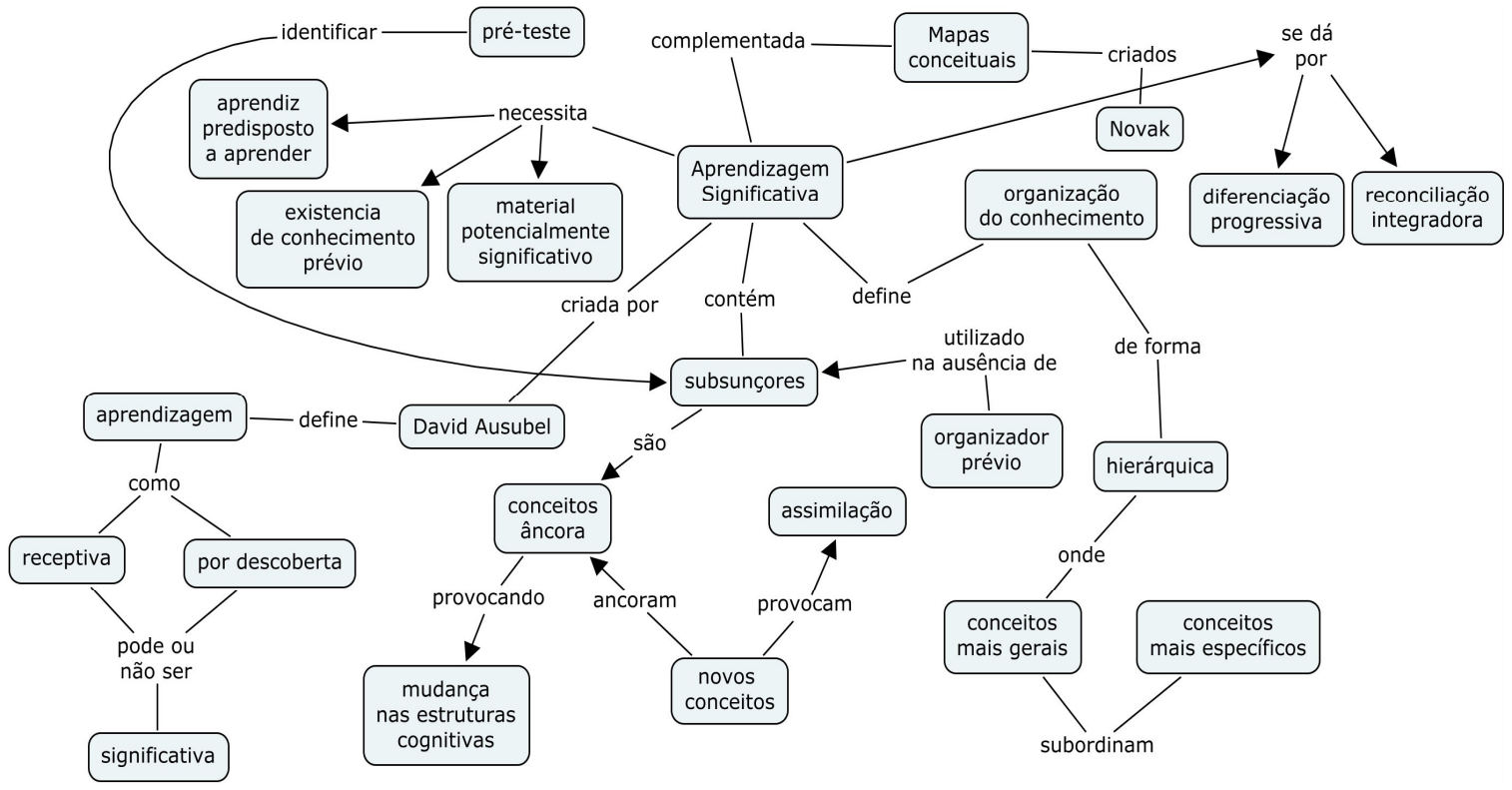

Figura 1. Mapa conceitual da teoria da aprendizagem significativa.

$\mathrm{Na}$ próxima seção é apresentada a caracterização do experimento didáticopedagógico em função dos pressupostos teóricos pré-estabelecidos.

\section{Caracterização do experimento}

A partir das teorias da aprendizagem significativa e da avaliação mediadora um modelo didático-pedagógico foi concebido para a prática em sala de aula com os alunos da disciplina de controle avançado do curso de bacharelado em engenharia de controle e 
automação do IFX (Instituto Federal X). O objetivo deste modelo é delinear o novo plano de aula da disciplina a partir do ferramental teórico apresentado, do conteúdo programático da disciplina, e a inclusão dos devidos instrumentos de coleta de dados. Estes instrumentos surgem como mecanismos de investigação da aprendizagem significativa

$\checkmark$ O novo plano de aula é desenvolvido para o acompanhamento da evolução cognitiva do aluno ao longo do período letivo.

$\checkmark$ O campo de aplicação do modelo é formado pelos alunos do curso de bacharelado em engenharia de controle e automação.

$\checkmark$ Durante o semestre letivo a disciplina de controle avançado possui um conteúdo programático a ser trabalhado com os alunos. Este conteúdo foi adaptado para uma nova proposta de aula incluindo os instrumentos e seguindo o ferramental teórico utilizado.

Na Figura 2 as etapas do processo de ensino-aprendizagem que convergem para o modelo didático-pedagógico são apresentadas.

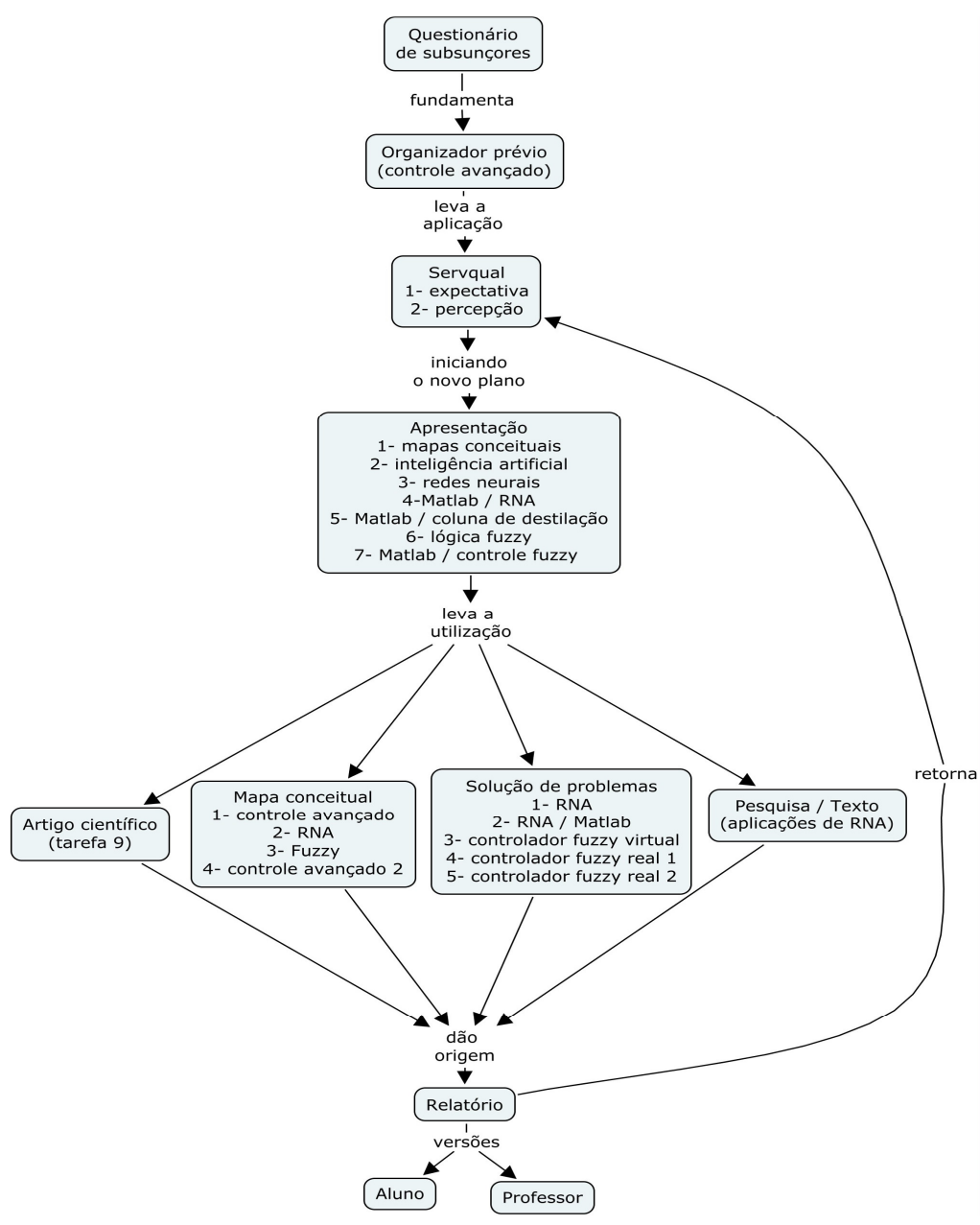

Figura 2. Mapa conceitual do novo plano de aula.

Lista de instrumentos utilizados: questionário de levantamento de subsunçores, questionário SERVQUAL, mapa conceitual, pesquisa e texto, relatório de alunos, relatório do professor, solução de problemas. A tabela 1 resume os instrumentos de pesquisa do experimento didático pedagógico.

Tabela 1. Instrumentos de coleta de dados do experimento didático-pedagógico. 


\section{Instrumentos de coleta de dados}

Questionário de levantamento de subsunçores: Dentro da perspectiva da aprendizagem significativa é necessário que o professor realize um levantamento do conhecimento prévio do indivíduo sobre o conteúdo ao qual ele deverá ser apresentado em aula expositiva.
Questionário SERVQUAL: Parasuraman et al. (1985)

apresentaram a metodologia que utilizaram para a criação da escala SERVQUAL. Trata-se de um processo iterativo de avaliação da qualidade de cinco empresas do ramo de serviços na década de 80 nos EUA e subseqüente verificação da consistência interna dos questionários através do coeficiente Alpha de Cronbach. A partir de cento e cinquenta itens os autores chegam a um questionário final com apenas vinte e dois itens, podendo estes itens ainda ser reduzidos.

Mapas conceituais: A construção destes mapas por parte dos alunos tem por objetivo verificar possíveis equívocos de relacionamento entre conceitos e conteúdos apresentados e direcionar a intervenção do professor para os pontos que requisitam auxílio. Os mapas podem ser discutidos para uma maior verificação do que o aluno estava pensando quando o construiu, embasando o registro de evolução do aluno ou mapa de atividade.

Relatório do aluno: Este relatório tem por finalidade registrar a percepção do aluno após realizar alguma tarefa que envolva os conteúdos adquiridos e os instrumentos utilizados para evidenciar a aprendizagem significativa.

Solução de problemas: Este último instrumento tem o intuito de propiciar a manifestação das capacidades do aluno ao se deparar com situações-problema próximas da sua prática profissional. Ao propor que eles resolvam problemas que não foram apresentados durante as aulas expositivas, os aprendizes são estimulados a transportar os conceitos adquiridos para esta nova situação procedendo em generalização e extensão para que possam solucionar a contanto os desafios propostos.

Os indícios da aprendizagem significativa serão verificados nos registros dos alunos por meio dos relatórios e principalmente, nos mapas conceituais construídos, bem como o processo de solução de problemas não previstos nas aulas expositivas que vai permitir a visualização da capacidade destes alunos em generalizar os conceitos e habilidades adquiridas e transpô-los para novas situações demonstrando compreensão.

\section{Resultados}

A partir de um novo plano de aula adaptado para a proposta pedagógica elaborada, os resultados obtidos são apresentados, opcionalmente, pelos mapas conceituais elaborados pelos alunos durante o experimento didático-pedagógico.

Os mapas conceituais retratam a evolução dinâmica em termos de estruturação cognitiva do indivíduo, operando sobre conceitos de redes de conceitos. Os indivíduos foram selecionados aleatoriamente para terem seus mapas conceituais apresentados como forma de identificar sua estruturação cognitiva dinâmica.

Os temas propostos para a construção dos mapas conceituais são relativos ao currículo da disciplina de controle avançado no curso de engenharia de controle e automação, dentre eles, redes neurais artificiais, lógica fuzzy, identificação de sistemas, controle fuzzy, etc. Nas Figuras 3, 4 e 5 são apresentados os mapas conceituais elaborados pelos alunos durante o experimento didático-pedagógico, estes mapas são apresentados da esquerda para a direita, respectivamente do mais antigo ao mais atual.
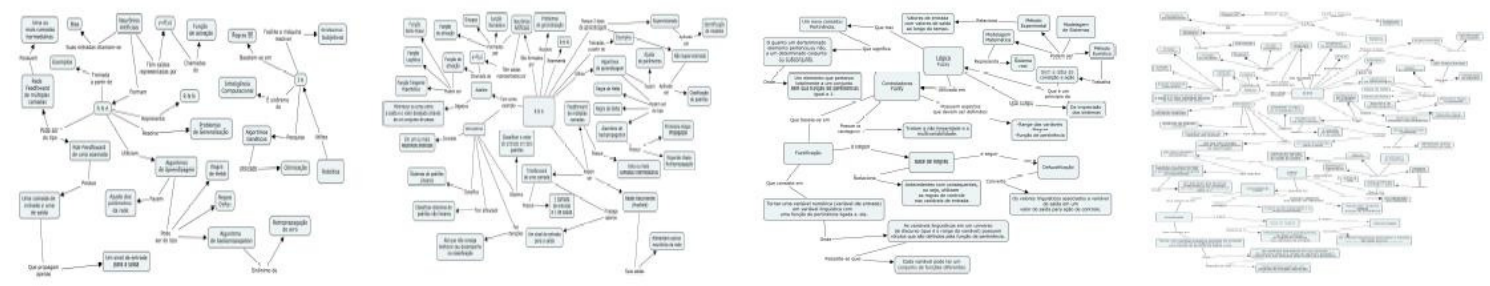

Figura 3. Mapas conceituais do aluno 1. 
A evolução dos mapas conceituais do aluno 1 evidencia uma mudança significativa na rede de conceitos deste aluno passando de um mapa inicial com um número de termos e conceitos reduzido operando basicamente sobre ramificação. Tratase de uma organização que se preserva nos demais mapas, todavia não se limita a conexões hierarquizadas simples, pois posiciona os conceitos de forma distribuída e com total interligação dos conceitos.
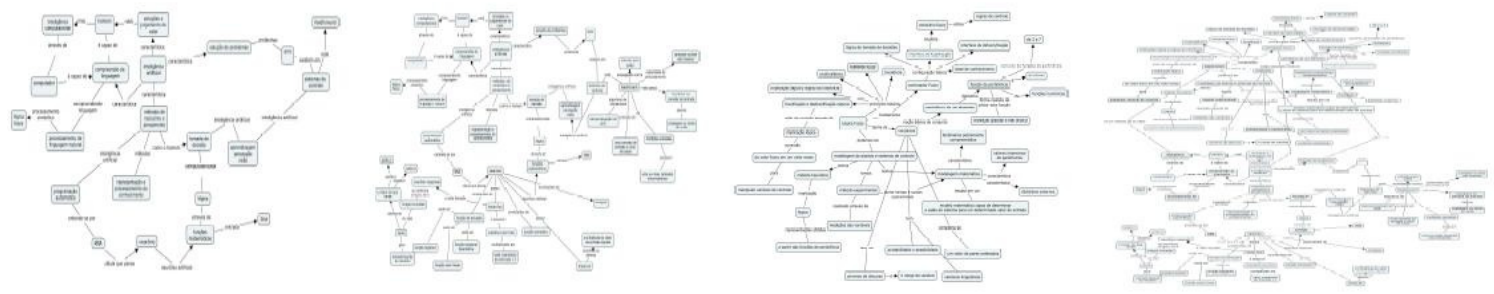

Figura 4. Mapas conceituais do aluno 2.

A evolução dos mapas conceituais do aluno 2 evidencia também um aumento na rede de conceitos, a partir do primeiro mapa e alcançando o mapa final. Percebe-se no último mapa que o aluno já consegue fazer conexões entre conceitos posicionados inicialmente distantes no mapa, isso demonstra um entendimento mais generalizado do domínio proposto. No mapa inicial a tendência é basicamente de hierarquização onde os conceitos mais gerais subordinam os mais particulares, organizando o conhecimento adquirido na forma de diferenciação progressiva.
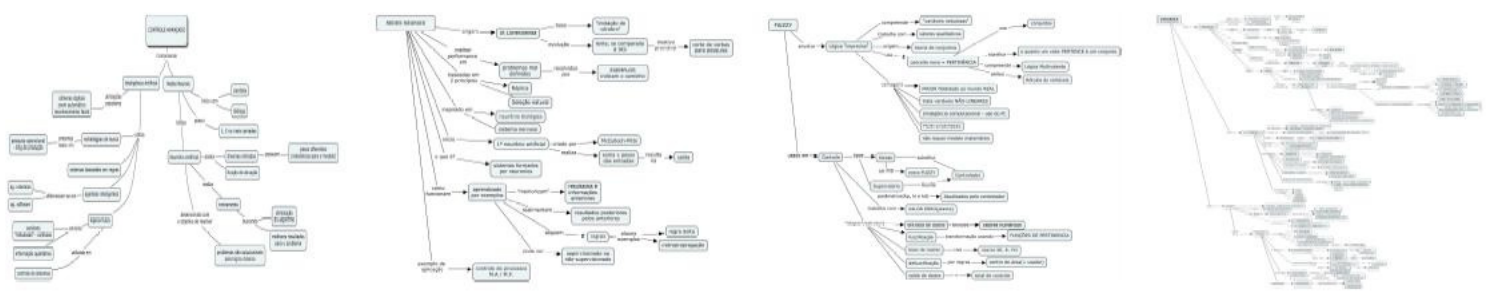

Figura 5. Mapas conceituais do aluno 3.

Os mapas conceituais do aluno 3 apresentam uma forte tendência da hierarquização, ramificação, derivação, desde o primeiro mapa até o último. Historicamente os primeiros mapas conceituais eram hierarquizados seguindo a forma dos mapas aqui analisados, porém os mapas com essa tendência evidenciam uma certa dificuldade do aluno em elaborar conexões mais complexas como ligações transversais, bem como generalização dos conceitos assimilados.

\section{Considerações finais}

A partir de uma lacuna existente no processo de ensino-aprendizagem de controle avançado em cursos de engenharia de controle e automação, este estudo propôs uma solução galgada em pressupostos teóricos para a verificação da aprendizagem, suprindo a referida lacuna.

Um modelo didático-pedagógico que converge para o plano de aula de uma nova prática docente é apresentado e os instrumentos para verificação da aprendizagem são apresentados e analisados sob a luz das teorias propostas, em especial os mapas conceituais.

Os resultados obtidos e apresentados na forma de evolução dinâmica dos mapas conceituais podem ser vistos como um extrato da organização cognitiva dos alunos investigados, pois se baseiam na forma como os conceitos estão estruturados e são representados pelos alunos. A hierarquização e ramificação são uma tendência, mas relações transversais também são construídas, e relacionando com a teoria da 
aprendizagem significativa podem-se verificar os seguintes conceitos: diferenciação progressiva e reconciliação integradora.

O aumento no número de conceitos dos mapas evidencia uma grande assimilação dos conceitos fornecidos pelos diferentes objetos de estudo e evidenciam que os alunos possuíam os subsunçores necessários para o conteúdo presente no currículo da disciplina. A partir destas evidências poder-se-á dizer que houve, nos alunos investigados, a manifestação da aprendizagem significativa, proporcionando ligações não arbitrárias e significativas na rede de conceitos do indivíduo.

\section{Referências bibliográficas}

AHLERT, A. A avaliação como um processo interno da prática pedagógica. Caderno de Educação Física: estudos e reflexões, Marechal Cândido Rondon, v. 4, n. 8, p. 119$125,2002$.

AUSUBEL, D. P., NOVAK, J. D. \& H. HANESIAN, H., Educational Psychology: A Cognitive View. New York: Holt, Rinehart\& Winston, 1978.

HOFFMANN, J. Avaliação Mediadora: uma prática em construção da pré-escola à Universidade. 8. ed., Porto Alegre: Mediação, 1996.

HOFFMANN, J. Avaliação mediadora: uma relação dialógica na construção do conhecimento. 1994. Disponível em http://www.crmariocovas.sp.gov.br. Acesso em: 20 set. 2009.

MOREIRA, M. A., A teoria da aprendizagem significativa e sua implementação em sala de aula. Brasília: Editora da UnB. 2006.

MOREIRA, M. A. e DIONISIO, P. H., Interpretação de Resultados de Testes de Retenção em Termos da Teoria de Aprendizagem de David Ausubel, In: Revista Brasileira de Física, Vol. 5, n 2, 1975.

MOREIRA, M. A., Mapas conceituais e aprendizagem significativa, Adaptado e atualizado, em 1997, de um trabalho com o mesmo título publicado em O ENSINO, Revista Galáico Portuguesa de Sócio-Pedagogia e Sócio-Linguística, Pontevedra/Galícia/Espanha e Braga/Portugal, $N^{\circ} 23$ a 28: 87-95, 1988.

NOVAK, J. D., A Theory of Education. Ithaca, NY: Cornell University Press. 1977.

NOVAK, J. D. \& CAÑAS, A. J. The theory underlying concept maps and how to construct them. Technical Report IHMC CmapTools 2006-01, Florida Institute for Human and Machine Cognition, Acessado em 15 de abril de 2010 em http://cmap.ihmc.us/Publications/ResearchPapers/TheoryUnderlyingConceptMaps.pdf., 2006.

PARASURAMAN, A., ZEITHAM, V. A., BERRY, L. L., A Conceptual Model of Service Quality and Its Implications for Future Research, Journal of Marketing, p. 41$50,1985$.

PIAGET, J. Epistemologia Genética, Martins Fontes, São Paulo, (Col. Psicologia e Pedagogia), 2007.

SCHNAID, F., TIMM, M. I., ZARO, M. A. Considerações sobre uso de modelo construtivista no ensino de Engenharia - disciplina de projeto, com graduandos e mestrandos. RENOTE - Revista Novas Tecnologias na Educação, Porto Alegre: UFRGS, v. 1, n. 1, 2003. 
SILVEIRA, F. P. R. A., Levantamento preliminar de habilidades prévias: subsídios para a utilização de mapas conceituais como recurso didático. In: Revista Eletrônica Experiências em Ensino de Ciência, v. 3, p. 85-96, 2008.

VALLIM, M. B. R, FARINES, J., CURY, J. E. R., Em direção à melhoria do ensino na área tecnológica: a experiência de uma disciplina de introdução à engenharia de controle e automação, In: Anais do XIII Congresso Brasileiro de Automática, FlorianópolisSC, Brasil, 2000. 